\title{
Socio-ecological Determinants of Under-five Mortality in Nigeria: Exploring the Interaction Effects of Neighbourhood Poverty and Solid Cooking Fuel
}

Chukwuechefulam Kingsley Imo ( $\square$ imochuksco@yahoo.com )

Adekunle Ajasin University

Research article

Keywords: Neighbourhood poverty, solid cooking fuel, under-five mortality, Nigeria

Posted Date: November 24th, 2020

DOl: https://doi.org/10.21203/rs.3.rs-113071/v1

License: (c) (1) This work is licensed under a Creative Commons Attribution 4.0 International License.

Read Full License 


\section{Abstract}

Background: In the context of global child health priority, under-five mortality remains considerably high with the current rate of 132 deaths per 1,000 live births in Nigeria, which translates to 1 in 8 children dying before his or her fifth birthday. This has been attributed to exposure of children to household air pollution due to environmental context and inefficient cooking practices. Therefore, this study examined the interaction effects of neighbourhood poverty and use of solid cooking fuels on under-five mortality in Nigeria.

Methods: Data for the study were drawn from the 2018 Nigeria Demographic and Health Survey and covered a weighted sample of 124,442 birth history of childbearing women who reported using cooking fuels in kitchens located within the house. Descriptive and analytical analyses were carried out, including frequency tables, Pearson's chi-square test, and multivariate using Cox proportional regression model.

Results: The findings of this study showed that the risks of under-five mortality were significantly higher for children whose mothers were found in the areas of high neighbourhood poverty (HR: 1.44, Cl: 1.341.54) and those whose mothers reported using solid cooking fuels within the house (HR: 2.26, Cl: 2.062.49). The results further showed that the risks of death significantly reduced for children whose mothers had secondary or tertiary education (HR: $0.82, \mathrm{Cl}: 0.75-0.90)$ and children of mothers whose partners had at least primary education, but increased for children of mothers who were rural residents (HR: $1.25, \mathrm{Cl}$ : 1.16-1.35); and those found in the North-east (HR: 1.31, Cl: 1.18-1.46) and North-west (HR: 1.84, Cl: 1.682.02), compared with those in the reference categories.

Conclusion: The risks of under-five mortality are significantly linked to areas of high neighbourhood poverty and use of solid cooking fuels in kitchens located within the house in Nigeria. There is the need for more pragmatic strategies to re-educate people, especially mothers on the need to use clean cooking fuels from the little resources they have to reduce the children's exposure to harmful emissions within the house.

\section{Background}

Under-five mortality (U5M), defined as the number of children dying before the fifth birthday (0-59 months) has universally remained unacceptably high. On the average, between 1990 and 2017, there was a 58\% decline in U5M across the globe, 118 countries have already achieved the sustainable development goal (SDG) 3 target of the U5M rate of less than 25 per 1,000 live births [1]. Although the world witnessed a tremendous reduction in child mortality, sub-Saharan Africa which Nigeria belongs is the only region with U5M rates of 76 deaths per 1,000 live births $[1,2]$. These deaths remain considerably high in Nigeria as the eighth highest in the world [3] and the highest in Africa [4]. Even going by the current U5M rate of 132 deaths per 1,000 live births, this implies that more than 1 in every 8 children in Nigeria dies before age 5 [2]. Despite the decline from 213 deaths per 1,000 live births in 1990 to 132 deaths per 1,000 live 
births in 2018 [2], the slow pace of decline in U5M has been attributed to poor progress in child survival interventions [5], including exposure to household air pollution due to inefficient cooking practices [6].

Globally, around 3 billion people cook with polluting open fires fuelled by biomass including wood, animal dung, crop waste and coal and most of these people are poor and live in low- and middle-income countries [6]. Consequently, 3.8 million people die prematurely annually from illness attributable to the household air pollution caused by the inefficient cooking practices of using solid fuels, while exposure to household air pollution almost doubles the risks for childhood pneumonia and is responsible for $45 \%$ of all pneumonia deaths in children less than 5 years old [6]. In Nigeria, the percentage of households using solid cooking fuels is high (79\%), with $61 \%$ using wood. This includes $87 \%$ of households in rural areas and $47.7 \%$ of households in urban areas [2]. Studies have shown that the use of some solid fuels has been associated with indoor air pollution, unsafe levels of toxic and mortality related cases in both adults and children [7-11]. Children are more susceptible to housing air pollution than adults since they spend most time indoors. They are at risk because they require a higher amount of air inhalation than adults, and their organs are not fully developed [12-13]. Hence, children from the households where solid fuels are the main sources of cooking amenities are more likely to experience acute respiratory infections (ARIs) because indoor air pollution is closely associated with the location of kitchen [14].

Poverty and child's health are connected in diverse ways. Children from less privileged households are more vulnerable to air pollution, poor sanitation among others, which are some of the risks of diverse diseases resulting in U5M $[3,15]$. A study has shown that poverty is negatively associated with child health [16]. No doubt, the absence substances that make life comfortable in the household as a result of poverty could have an adverse effect on a child's health outcome. Children who are living in poverty are more likely to experience respiratory health problems [17]. Previous studies observed that the majority of susceptible children are exposed to harmful emissions of biomass smoke at home, which significantly increases the risk for acute lower respiratory tract infections, upper respiratory tract infections and asthma, and pneumonia [18-20]. Besides, most under-five children's deaths caused by ARIs are closely associated with environmental factors including the use of solid fuels [21-22]. Therefore, avoiding the use of solid fuels such as wood stove seems as preventive measures to reduce the risks of ARIs for under-five children [23].

Socio-economic and demographic factors are akin to the status of children's health. Mother's education is negatively associated with the incidence of children's diseases which could result in deaths [24-25]. In addition to the mother's education, household wealth influences the choice of household fuel for cooking [26]. Thus, increasing the level of education among women and in association with other socio-economic and demographic factors significantly reduces the incidence of U5M [27]. Educated mothers tend to seek a healthy environment and health care facility for their children. Under-five children's health outcomes are tied to mother's education, occupation, and wealth status among others [28]. The choice of cooking amenities and rural location are making much difference in terms of health challenges including ARIs affecting children's health [29]. Hence, the high prevalence of under-five deaths in rural areas has been attributed to the predominant negative practices, as well as a low level of education and wealth status 
[30]. In Nigeria, the geo-political zones have significant effects on the unevenness in childhood mortality rates [31]. Attributably, areas with enhanced accessibility to clean cooking fuels tend to record reduced under-five deaths.

There have been few studies that investigated the association between household cooking fuels and health outcome of under-five children in Nigeria. Most of these studies were limited to solid cooking fuels by adopting binary logistic regression for data analyses [32]; contributory factors to regional inequalities in ARIs symptoms among under-five children [29] and household materials as predictors of U5M using 2013 NDHS [33]. Also, the observations of some studies from other countries that examined the effect of household air pollution on people's health reached contradictory conclusions [34-36]. However, in the context of global child health priority, no previous studies have examined the interaction effects of neighbourhood poverty and using solid cooking fuels within the house on U5M. The implication is that the findings of these studies might be limited in informing strategic interventions and policy formulation concerning the interaction effects of neighbourhood poverty and use of solid cooking fuels on under-five children's health outcome. The need for this study becomes pertinent, especially in Nigeria which is one of the five countries with the largest populations living in extreme poverty and are home to about $23 \%$ of the world's poor [37]. No doubt, poverty plays a role in the choice of solid cooking fuels that exposes underfive children to harmful emissions of biomass smoke at home.

Assessing the contributory role of neighbourhood poverty simply described as the percentage of households in the poorest quintile of the wealth index [38] and deprivation from a broader perspective which is considered as a lack of basic needs, possibly resulting to the use of solid cooking fuels [39], which directly impact people's health [40] becomes important. Though, studies have shown the significant association between poverty and child health outcomes [41-42]. This study investigated the interaction effects of neighbourhood poverty and use of solid cooking fuels on U5M using the latest NDHS data and Cox proportional regression analyses considered most appropriate for examining the risk of U5M. Adopting the implications of the findings of this study is essential for futuristic strategies towards developing more strategies towards ending poverty in all its forms, attaining universal access to affordable, reliable, sustainable and modern energy, as well as reducing U5M in Nigeria by 2030.

\section{Theoretical Framework}

\section{Socio-ecological models}

This study adopted socio-ecological models to explain the interaction effects of neighbourhood poverty and use of solid cooking fuels on U5M. The models recognize individuals as embedded within larger social systems and describe the interactive characteristics of individuals and environments that underlie health outcomes $[43,44]$. Ecological models specific to health promotion are multifaceted, targeting environmental, behavioural, and social policy changes that help individuals make healthy choices in their daily lives [45]. The models are unique in the study of the risks of death by taking into account the physical environment and its relationship to people at intrapersonal, interpersonal, organizational, 
community, and public policy levels. Studies have suggested that socio-ecological models offer promising results in preventing many public health problems [46, 47]. In line with socio-ecological models, Stokols $[44,47]$ observed that the social, physical, and cultural aspects of an environment have a cumulative effect on health. He maintained that the environment itself is multilayered since institutions and neighbourhoods are embedded in larger social and economic structures, and that the environmental context might influence the health of individual people differently, depending on their unique beliefs and practices. As a result, creating sustainable health improvements is most effective when all of these factors are targeted simultaneously. It is, therefore, hypothesised that coming from areas of high neighbourhood poverty influences the use of solid cooking fuels, which invariably influence children's health outcome.

\section{Methods}

\section{Data source}

This study was conducted in Nigeria and the data were obtained from the birth recode data file of the 2018 Nigeria Demographic and Health Survey (NDHS). The NDHS 2018 is a cross-sectional study and the sixth survey of its kind to be implemented by the National Population Commission (NPC) in Nigeria. Although the 2006 National Population and Housing Census of the Federal Republic of Nigeria (NPHC) conducted by NPC did not provide the number of households and population for each Enumeration Area (EA), population estimates were published for 774 Local Government Areas (LGAs). A combination of information from cartographic material demarcating each EA and the LGA population estimates from the census was used to identify the list of EAs, estimate the number of households, and distinguish EAs as urban or rural for the survey sample frame. The survey provides up-to-date information on demographic and health indicators in Nigeria. The sample was selected using a stratified, two-stage cluster design, with enumeration areas (EAs) as the sampling units for the first stage. The second stage was a complete listing of households carried out in each of the 1,400 selected EAs. A representative sample of 41,668 households was selected for the survey. Data were generated from 41,821 women age 15-49 and 13,311 men aged 15-59. A detailed report of the data collection methods and procedures for 2018 NDHS has been published elsewhere [2]. The analyses for this study covered a weighted sample of 124,442 birth history within 5 years before the survey to improve the representativeness of the data from the group of women interviewed in the survey (i.e. 2013-2018). The group of women whose births history was included in the sample were those within the childbearing age of 15-49 years and who reported to have given birth to at least a child between 2013 and 2018, irrespective of socio-economic and demographic backgrounds. Also, the women were those who reported using cooking fuels in kitchens located within the house.

\section{Variables measurements}

\section{Outcome variable:}


The analysis for this study was child-based. Hence, data from the birth recode of 2018 NDHS were utilised and analyses covered the live births born to women between 2013 and 2018 period. Therefore, the outcome variable in this study is under-five mortality - defined as the risk of a live-born child dying between birth and the fifth birthday (0-59 months). This was measured as the duration of survival since birth in months. Survival time was the age at death, while children who were alive by the survey data were censored at their age.

\section{Explanatory variables:}

The key explanatory variables in this study were neighbourhood poverty and solid cooking fuel. Neighbourhood poverty was measured as the percentage of households in the poorest quintile of the wealth index [38]. The use of solid cooking fuels was derived from the type of cooking fuel used within the house. Hence, solid fuels include coal/liquate, charcoal, wood, straw/shrubs/grass, agricultural crop and animal dung, non-solid fuels were considered to be electricity, gas and kerosene used for cooking in the kitchens located within the house. The use of solid fuels for cooking was used as a proxy because exposure to smoke inside the home rather than in a separate building or outdoors, from cooking with solid fuels has potentially harmful health effects [2, 32]. Besides, apart from the key explanatory variables, co-variables included in the analyses were maternal age, mother's educational attainment, father's educational attainment, mother's employment status, father's employment status, place of residence and region. To make interpretations simpler and more meaningful, some variables were regrouped from their original categories in the data-sets. For instance, age: $15-24 / 25-34 / 35+$ years; and educational attainment: no education/ primary/secondary or tertiary (see Box 1 below). The choice and selection of the key explanatory variables and co-variables for the study were informed by their documented significant association in the literature with mortality and other related potential health implications. The summary of variables is presented below. 
Box 1

Summary of variables

\begin{tabular}{|c|c|c|}
\hline $\begin{array}{l}\text { Variable } \\
\text { category }\end{array}$ & Variable & Description \\
\hline Outcome & Under-five mortality & $\begin{array}{l}\text { This is dying before the fifth birthday ( } 0-59 \text { months) } \\
\text { categorised as yes (died between } 0 \text { and } 59 \text { months) and no } \\
\text { (alive) }\end{array}$ \\
\hline \multirow[t]{2}{*}{$\begin{array}{l}\text { Main } \\
\text { explanatory } \\
\text { variables }\end{array}$} & $\begin{array}{l}\text { Neighbourhood } \\
\text { poverty }\end{array}$ & $\begin{array}{l}\text { The percentage of households in the poorest quintile of the } \\
\text { wealth index, grouped into: no (reference category) and yes } \\
\text { [38]. }\end{array}$ \\
\hline & $\begin{array}{l}\text { Type of cooking } \\
\text { fuel (solid fuel was } \\
\text { used as a proxy) }\end{array}$ & $\begin{array}{l}\text { The use of cooking fuel in kitchens located within the house. It } \\
\text { was grouped as: non-solid cooking fuels (reference category) } \\
\text { and solid cooking fuels. }\end{array}$ \\
\hline \multirow[t]{7}{*}{$\begin{array}{l}\text { Co- } \\
\text { variables }\end{array}$} & Maternal age & $\begin{array}{l}\text { The age of mothers was regrouped as: } 15-24 \text { (reference } \\
\text { category), } 25-34 \text { and } 35-49 \text {. }\end{array}$ \\
\hline & $\begin{array}{l}\text { Mother's education } \\
\text { attainment }\end{array}$ & $\begin{array}{l}\text { The highest level of formal education attained by the mother, } \\
\text { grouped into: none (reference category), primary and } \\
\text { secondary or higher. }\end{array}$ \\
\hline & $\begin{array}{l}\text { Father's education } \\
\text { attainment }\end{array}$ & $\begin{array}{l}\text { The highest level of formal education attained by the fathers, } \\
\text { grouped into: none (reference category), primary and } \\
\text { secondary or higher. }\end{array}$ \\
\hline & $\begin{array}{l}\text { Mother's } \\
\text { employment status }\end{array}$ & $\begin{array}{l}\text { This is the current employment status of mothers. It was } \\
\text { grouped into } 2 \text { groups; not working (reference category) and } \\
\text { currently working. }\end{array}$ \\
\hline & $\begin{array}{l}\text { Father's } \\
\text { employment status }\end{array}$ & $\begin{array}{l}\text { This is the current employment status of fathers. It was } \\
\text { grouped into } 2 \text { groups; not working (reference category) and } \\
\text { currently working. }\end{array}$ \\
\hline & Place of residence & $\begin{array}{l}\text { This is the place where the respondents live. It is categorised } \\
\text { as: urban (reference category) and rural. }\end{array}$ \\
\hline & Region & $\begin{array}{l}\text { This has to do with parts of the country categorised as: North- } \\
\text { central (reference category), North-east, North-west, South-east, } \\
\text { South-south and South-west. }\end{array}$ \\
\hline
\end{tabular}

Note: 'Reference category' is the most common category in each of the variables

\section{Statistical analysis}

Three levels of analysis (univariate, bivariate and multivariate) were employed in the study. Pearson chisquare test was used at the bivariate level to investigate the relationship between the outcome variable (under-five mortality) and each of the key explanatory variables and co-variables. At the multivariate level, Cox proportional regression analysis was used to examine the risk of under-five mortality. The Cox 
regression procedure is a useful analytical technique for the analysis of survival data. At the multivariate level, three models were fitted in all. Model 1 presents the univariate hazard ratio (HR) showing the relationship between under-five mortality and the key explanatory variables, as well as co-variables. Model 2 considered the adjusted HR for the effect of the two key explanatory variables. Model 3 adjusted for all the selected key explanatory and co-variables. The results were presented as HR with $95 \%$ confidence intervals (Cls). A variable with HR greater than 1.00 implied that the variable increases the likelihood of the outcome (under-five mortality), while it is the opposite when the HR is less than 1.00. All the analyses were conducted using Stata software (version 14).

\section{Results}

\section{Percentage distribution of all the study variables of the sample}

The percentage distributions of the socio-demographic and ecological factors are presented in Table 1. The largest proportion of the children (59.0\%) were children of mothers aged 35-49. Concerning educational attainment, mothers with no formal education had the largest number of children $(50.0 \%)$, while $42.3 \%$ were children of mothers whose husbands had secondary or tertiary education. Considering the employment status, over two-thirds of the children (74.2\%) were children of mothers who were currently working. An overwhelming majority of the children (96.0\%) were born of mothers whose partners reported to be currently working. The mothers who were rural residents had the majority of children $(65.4 \%)$ in the sample. Also, the largest proportion of children (31.3\%) and the lowest proportion of children (9.8\%) were children of mothers in the North-west and South-south, respectively. With respect to the key explanatory variables, about $25 \%$ of the children were children of mothers found in the areas of high neighbourhood poverty. Over two-thirds of the children (86.5\%) were born of mothers who reported using solid fuels for cooking within the house. 
Table 1

Distribution of all the study variables of the sample

\section{Socio-economic and demographic} characteristics

Variable/category

Maternal age

$15-24$

$25-34$

$35-49$

Mother's educational attainment

None

Primary

Secondary or higher

Father's educational attainment

None

Primary

Secondary or higher

Mother's employment status

Not working

Currently working

Father's employment status

Not working

Currently working

Place of residence

Urban

Rural

Region

North-central

North-east
Socio-ecological variables

Number(\%) Variable/category Number(\%)

Neighbourhood poverty

9,681(7.7) No

41,395(33.3) Yes

$30,503(24.5)$

73,366(59.0) Type of cooking fuel

Non-solid cooking fuels

$16,750(13.5)$

62,169(50.0) Solid cooking fuels 107,692(86.5)

$24,618(19.8)$

$37,655(30.3)$

$46,301(40.5)$

$19,659(17.2)$

$48,278(42.3)$

$32,139(25.8)$

$92,303(74.2)$

$4,551(4.0)$

$109,687(96.0)$

$43,091(34.6)$

$81,351(65.4)$
$21,182(17.0)$

$25,698(20.7)$ 


\section{Socio-economic and demographic characteristics}

North-west

South-east

South-south

South-west
Socio-ecological

variables

\section{Socio-economic and demographic factors associated with under-five mortality}

$38,905(31.3)$

$13,586(10.9)$

$12,173(9.8)$

$12,898(10.4)$

The bivariate relationship between under-five mortality and selected socio-economic, as well as demographic variables presented in Table 1 showed that all the variables were significantly associated with under-five mortality. The results showed a high percentage of under-five deaths among children of mothers aged 35-49 (15.7\%) and low among children of those aged 15-24 (11.4\%; $p<0.001)$. As expected, the results further showed that high percentage of under-five deaths were reported among children of mothers with no formal education $(18.6 \% ; p<0.001)$, as well as children of mothers whose partners had no formal education $(19.8 \% ; p<0.001)$. The results further revealed that more under-five deaths occurred among children of mothers who were not working $(16.2 \% ; p<0.001)$; children of mothers whose partners were not working $(15.9 \% ; p<0.01)$ and children of mothers who were rural residents $(16.3 \% ; p<0.001)$. Results also showed that under-five deaths among mothers ranged from $15.6 \%$ in the North-east to $7.7 \%$ in the South-west. 
Table 2

Socio-economic and demographic factors associated with under-five mortality

\begin{tabular}{|c|c|c|c|c|}
\hline & \multicolumn{4}{|c|}{ Under-five (0-59 months) } \\
\hline & Alive & Dead & Total number & Chi-square \\
\hline Variable/category & $N=106,647$ & $N=17,795$ & $N=124,442$ & \\
\hline Maternal age & & & & $277.6^{\star \star \star}$ \\
\hline $15-24$ & $8,578(88.6)$ & $1,103(11.4)$ & 9,681 & \\
\hline $25-34$ & $36,190(87.4)$ & $5,205(12.6)$ & 41,395 & \\
\hline $35-49$ & $61,879(84.3)$ & $11,487(15.7)$ & 73,366 & \\
\hline Mother's educational attainme & & & & $210.0 * \star \star$ \\
\hline None & $50,637(81.5)$ & $11,532(18.6)$ & 62,169 & \\
\hline Primary & $21,381(86.8)$ & $3,237(13.2)$ & 24,618 & \\
\hline Secondary or higher & $34,629(92.0)$ & $3,026(8.0)$ & 37,655 & \\
\hline Father's educational attainmer & & & & $190.3^{\star \star \star}$ \\
\hline None & $37,129(80.2)$ & $9,172(19.8)$ & 46,301 & \\
\hline Primary & $17,043(86.7)$ & $2,616(13.3)$ & 19,659 & \\
\hline Secondary or higher & $43,534(90.2)$ & $4,744(9.8)$ & 48,278 & \\
\hline Mother's employment status & & & & $139.4^{\star \star \star}$ \\
\hline Not working & $26,905(83.7)$ & $5,234(16.3)$ & 32,139 & \\
\hline currently working & $76,742(86.4)$ & $12,561(13.6)$ & 92,303 & \\
\hline Father's employment status & & & & $8.2^{\star \star}$ \\
\hline Not working & $3,826(84.1)$ & $725(15.9)$ & 4,551 & \\
\hline currently working & $93,880(85.6)$ & $15,807(14.4)$ & 109,687 & \\
\hline Place of residence & & & & $797.2^{\star \star \star}$ \\
\hline Urban & $38,588(89,6)$ & $4,503(10.4)$ & 43,091 & \\
\hline Rural & 68,059(83.7) & $13,292(16.3)$ & 81,351 & \\
\hline Region & & & & $300.3^{\star \star \star}$ \\
\hline North-central & 18,805(88.8) & $2,377(11.2)$ & 21,182 & \\
\hline
\end{tabular}




\begin{tabular}{|llll|}
\hline \multicolumn{4}{|c|}{ Under-five (0-59 months) } \\
\hline North-east & $21,691(84.4)$ & $4,007(15.6)$ & 25,698 \\
\hline North-west & $30,600(78.7)$ & $8,305(21.3)$ & 38,905 \\
\hline South-east & $12,452(91.7)$ & $1,134(8.3)$ & 13,586 \\
\hline South-south & $11,195(92.0)$ & $978(8.0)$ & 12,173 \\
\hline South-west & $11,904(92.3)$ & $994(7.7)$ & 12,898 \\
\hline Note: **p<0.01;*** $<0.001$ & & & \\
\hline
\end{tabular}

\section{Socio-ecological factors associated with U5M}

Table 3 presents the bivariate relationship between U5M and socio-ecological factors (key explanatory variables). The results showed that the two selected key explanatory variables were significantly associated with U5M. The relationship between neighbourhood poverty and under-five mortality showed that a high percentage of under-five deaths occurred among mothers found in the areas of high neighbourhood poverty $(19.6 \% ; p<001)$. Considering the type of cooking fuel within the house, the percentage of under-five deaths was higher among children of mothers living in houses where solid fuels were used for cooking $(15.5 \%)$, relative to their counterparts in households where non-solid fuels were used for cooking within the house $(6.7 \% ; p<0.001)$.

Table 3

Socio-ecological factors associated with U5M

\begin{tabular}{|lllll|}
\hline \multicolumn{5}{|c|}{ Under-five (0-59 months) } \\
\hline & Alive & Dead & Total number & Chi-square \\
\hline Variable/category & $\mathrm{N}=106,647$ & $\mathrm{~N}=17,795$ & $\mathrm{~N}=124,442$ & \\
\hline Neighbourhood poverty & & & & $918.7^{\star \star \star}$ \\
\hline No & $82,116(87.4)$ & $11,823(12.6)$ & 93,939 & \\
\hline Yes & $24,531(80.4)$ & $5,972(19.6)$ & 30,503 & \\
\hline Type of cooking fuel & & & & \\
\hline Non-solid cooking fuels & $15,620(93.3)$ & $1,130(6.7)$ & 16,750 & \\
\hline Solid cooking fuels & $91,027(84.5)$ & $16,665(15.5)$ & 107,692 & \\
\hline Note: ${ }^{* \star *}$ < $<0.001$ & & & & \\
\hline
\end{tabular}

Risk factors of U5M: survival analysis 
The results of the survival analysis are presented in Table 4. In all, three models were fitted to examine the risk factors of under-five mortality. Model 1 presents the unadjusted HR showing the relationship between under-five mortality and the two key explanatory and selected co-variables. Model 2 considered the adjusted HR for the effect of the two key explanatory variables. Model 3 adjusted for all the selected key explanatory and co-variables.

Results from the unadjusted hazard model (Model 1; Table 4) showed a significant relationship between the risk of under-five mortality and all the variables. Regarding socio-ecological factors, the results showed that risks of under-five deaths significantly increased for children whose mothers were found in the areas of high neighbourhood poverty (HR: 1.63, Cl: 1.51-1.75) and children of mothers who used solid fuels for cooking within their houses (HR: 2.53, Cl: 2.31-2.78), compared with their counterparts in the reference categories. Considering socio-economic and demographic factors, the risks of under-five deaths significantly reduced for children of mothers aged 25-34 years (HR: 0.89, Cl: 0.82-0.96); children of mothers and those whose partners had at least primary education and children of mothers who were currently working (HR: $0.78, \mathrm{Cl}: 0.73-0.83)$, relative to those in the reference categories. The results in Model 1 further showed that the risks of under-five deaths significantly increased for children of mothers who were rural residents (HR: 1.76, Cl: 1.62-1.90); and children of mothers found in the North-east (HR: 1.47, Cl: 1.32-1.64) and North-west (HR: 2.05, Cl: 1.87-2.26) relative to those in the reference categories. But the risks of death for children of mothers found in the South-east, South-south and South-west.

The adjusted HR for the two socio-ecological factors in Model 2 (Table 4) showed similar results observed in Model 1. The results showed that risks of under-five deaths significantly increased for children whose mothers were found in the areas of high neighbourhood poverty (HR: 1.44, Cl: 1.34-1.54) and children of mothers who used solid fuels for cooking within their houses (HR: 2.26, Cl: 2.06-2.49), compared with their counterparts in the reference categories. After adjusting for the socio-economic and demographic variables in Model 3 , the results revealed significantly higher risks of death for children of mothers who used solid fuels for cooking within their houses (HR: 1.22, Cl: 1.09-1.37), relative to those in the reference category. The results in Model 3 further showed that the risks of death significantly reduced for children whose mothers had secondary or tertiary education (HR: $0.82, \mathrm{Cl}: 0.75-0.90)$ and children of mothers whose partners had at least primary education. On the other hand, the risks of under-five death were higher among children of mother residing in rural areas (HR: 1.25, Cl: 1.16-1.35), as well as children of mothers children of mothers found in the North-east (HR: 1.31, Cl: 1.18-1.46) and North-west (HR: $1.84, \mathrm{Cl}: 1.68-2.02)$, compared with those in the reference categories. 
Table 4

Hazard ratio (HR) and 95\% confidence interval (Cl) for socio-ecological and demographic factors associated with U5M, NDHS 2018

\begin{tabular}{|c|c|c|c|}
\hline & Model 1 & Model 2 & Model 3 \\
\hline Variable/category & $\mathrm{HR}(95 \% \mathrm{Cl})$ & $\mathrm{HR}(95 \% \mathrm{Cl})$ & $\mathrm{HR}(95 \% \mathrm{Cl})$ \\
\hline \multicolumn{4}{|l|}{ Neighbourhood poverty } \\
\hline No $(\mathrm{RC})$ & 1.00 & 1.00 & 1.00 \\
\hline Yes & $1.63(1.51-1.75)^{\star \star \star}$ & $1.44(1.34-1.54)^{\star \star \star}$ & $1.06(0.99-1.14)$ \\
\hline \multicolumn{4}{|l|}{ Type of cooking fuel } \\
\hline None solid cooking fuel (RC) & 1.00 & 1.00 & 1.00 \\
\hline Solid cooking fuel & $2.53(2.31-2.78)^{\star \star \star}$ & $2.26(2.06-2.49)^{\star \star \star}$ & $1.22(1.09-1.37)^{\star \star}$ \\
\hline \multicolumn{4}{|l|}{ Maternal age } \\
\hline $15-24(\mathrm{RC})$ & 1.00 & & 1.00 \\
\hline $25-34$ & $0.89(0.82-0.96)^{\star \star}$ & & $0.97(0.89-1.05)$ \\
\hline $35-49$ & $0.95(0.87-1.02)$ & & $1.05(0.96-1.14)$ \\
\hline \multicolumn{4}{|l|}{ Mother's educational attainment } \\
\hline None (RC) & 1.00 & & 1.00 \\
\hline Primary & $0.67(0.62-0.72)^{\star \star \star}$ & & $1.03(0.96-1.11)$ \\
\hline Secondary or higher & $0.40(0.37-0.43)^{\star \star \star}$ & & 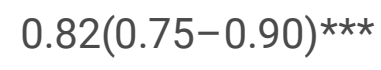 \\
\hline \multicolumn{4}{|l|}{ Father's educational attainment } \\
\hline None (RC) & 1.00 & & 1.00 \\
\hline Primary & $0.65(0.60-0.70)^{\star \star \star}$ & & $0.89(0.83-0.95)^{\star \star \star}$ \\
\hline Secondary or higher & $0.47(0.44-0.50)^{\star \star \star}$ & & $0.75(0.71-0.81)^{\star \star \star}$ \\
\hline \multicolumn{4}{|l|}{ Mother's employment status } \\
\hline Not working (RC) & 1.00 & & 1.00 \\
\hline currently working & $0.78(0.73-0.83)^{\star \star \star}$ & & $1.02(0.96-1.09)$ \\
\hline \multicolumn{4}{|l|}{ Father's employment status } \\
\hline Not working (RC) & 1.00 & & 1.00 \\
\hline currently working & $0.88(0.77-1.01)$ & & $1.06(0.95-1.19)$ \\
\hline
\end{tabular}

Note: ${ }^{*} \mathrm{p}<0.01 ;{ }^{* *} \mathrm{p}<0.001 ; \mathrm{RC}=$ Reference category 


\begin{tabular}{|c|c|c|c|}
\hline & Model 1 & Model 2 & Model 3 \\
\hline \multicolumn{4}{|l|}{ Place of residence } \\
\hline Urban (RC) & 1.00 & & 1.00 \\
\hline Rural & $1.76(1.62-1.90)^{\star \star \star}$ & & $1.25(1.16-1.35)^{\star \star \star}$ \\
\hline \multicolumn{4}{|l|}{ Region } \\
\hline North-central (RC) & 1.00 & & 1.00 \\
\hline North-east & $1.47(1.32-1.64)^{\star \star \star}$ & & $1.31(1.18-1.46)^{\star \star \star}$ \\
\hline North-west & $2.05(1.87-2.26)^{\star \star \star}$ & & $1.84(1.68-2.02)^{\star \star \star}$ \\
\hline South-east & $0.74(0.63-0.86)^{\star \star \star}$ & & $0.93(0.80-1.07)$ \\
\hline South-south & $0.74(0.65-0.84)^{\star \star \star}$ & & $0.90(0.79-1.03)$ \\
\hline South-west & $0.66(0.58-0.76)^{\star \star \star}$ & & $0.92(0.80-1.05)$ \\
\hline
\end{tabular}

\section{Discussion}

The health outcomes of individuals have been documented to be influenced by poverty and household air pollution; therefore, this study examined the socio-ecological determinants of under-five mortality with a special focus on the interaction effects of neighbourhood poverty and use of solid cooking fuels. The results of this study established that being found in the areas of high neighbourhood poverty and use of solid cooking fuels within the house are indeed important aspects for the risks of U5M in Nigeria. Therefore, interventions aimed at impacting under-five children's health outcome might benefit from a strength-based approach that underscores the interaction effects of neighbourhood poverty and use of solid cooking fuels within the house in the lives of children.

About one-quarters of the children were born of mothers found in the high neighbourhood poverty and an overwhelming majority of the children (86.5\%) were of mothers who used solid fuels for cooking within the house. The bivariate results showed that coming from areas of high neighbourhood poverty and use of solid cooking fuels within the house are significantly associated with U5M. These results have some policy implications in line with SDGs' targets of achieving the sustainable development goals' targets of attaining universal access to affordable, reliable, sustainable and modern energy, as well as reducing under-five deaths by less than 25 per 1,000 live births is needed in Nigeria.

The findings from Cox proportional regression analyses of the study revealed that the risks of under-five deaths were significantly higher among children whose mothers were found in the areas of high neighbourhood poverty than those in the low neighbourhood poverty (Table 4, Model 2). The finding corroborates previous studies that living under poverty is negatively associated with child health [16-17]. 
It further gives credence to other studies that children from less privileged households are more vulnerable to poor sanitation, including household air pollution among others, which are some of the risks of diverse diseases resulting to under-five mortality $[3,15]$. Also, the study showed that children of mothers who used solid fuels for cooking within the house are at a greater risk of U5M (Table 4, Model 2). This finding validates the observations that most under-five deaths are closely associated with environmental factors including the use of solid fuels for cooking within the house [21-22]. It further explains that the cause most under-five children's deaths are caused by risks of ARIs, which are closely associated with environmental factors including the use of solid fuels for cooking [19-22].

After adjusting for all the selected socio-economic and demographic factors in Model 3 , the findings showed that mother's education, father's education, place of residence and region were significantly associated with the risks of under-five deaths. For instance, the study revealed that parents having formal education significantly reduced the risks of under-five deaths, which is validated by previous studies [24$25,27]$. Plausibly, the choice of household cooking fuels which invariably influences the risks of underfive deaths could be determined by the levels of education of both mother and father. The finding on the influence of rural area on the risks of under-five deaths is expected considering the proportion of children whose mothers were rural residents. This result has some policy implications for more pragmatic strategies with a special focus on the rural dwellers towards poverty eradication, as well as achieving universal access to affordable, reliable, sustainable and modern energy to improve under-five health outcomes in Nigeria. Though, previous studies have attributed the influence of rural area on the risks of under-five deaths to the predominant negative practices [30] and health challenges including ARIs affecting under-five children's health outcome in rural areas [29]. Additionally, the findings on regional variations in the risks of U5M, especially among children of mothers found in the North-east and Northwest indicated the plausible influence of regional-level of high neighbourhood poverty and use of solid fuels for cooking. This could further explain the reason for higher rates of under-five deaths recorded in the North-west and North-east (187 deaths and 134 deaths per 1,000 live births, respectively), compared to the rate in the country at large [2].

\section{Conclusion}

The number of deaths among under-five children in the face of various factors remains a problem in Nigeria and estimated to be the highest in Africa. This study established that the risks of U5M were significantly linked to children of mothers found in the areas of high neighbourhood poverty and households where solid cooking fuels are used in kitchens located within the house in Nigeria. The findings further revealed that amidst coming from areas of high neighbourhood poverty and use of solid cooking fuels within the house, mother's education, father's education, place of residence and region were significantly key predictors associated with the risks of under-five deaths. Hence, the use of solid cooking fuels within the house which results to the emission of harmful smoke invariably influencing the risks of under-five deaths could be determined by areas of high neighbourhood poverty, as well as socioeconomic and demographic factors. Therefore, there is the need to empower and re-educate people, especially disadvantaged mothers in areas of high neighbourhood poverty to adopt the use of clean fuels 
for cooking to improve the health outcome of children. Government and non-governmental organisations should initiate mitigation and more adaptation strategy by empowering mothers and discouraging them from using solid cooking fuels within the house to reduce harmful emissions and child health consequences.

\section{Policy Implication}

Globally, most scientific shreds of evidence on the associations between the use of solid cooking fuels and health have grown considerably and helped in adopting preventive measures that are linked to good health management within the neighbourhood. However, from a policy point of view, there is a need for formulation of guidelines on healthy housing and environmental management including the need to end poverty and avoid the use of solid fuels for cooking within the households. These make children vulnerable to poor sanitation and household air pollution which are some of the risks of diverse diseases resulting in U5M. The findings of this study on the interaction effects of neighbourhood poverty and use of solid cooking fuels within the house on under-five mortality, using the latest NDHS have several policy implications for ending poverty in all its forms, attaining universal access to affordable, reliable, sustainable and modern energy, as well as reducing U5M by less than 25 per 1,000 live births by 2030 in Nigeria. Additionally, adopting the findings of this study would enable policy-makers, including government and non-governmental organisations to re-strategise and re-educate people on the need use clean cooking fuels from the little resources they have to reduce the children's risks of vulnerability to harmful emissions within the house.

\section{Abbreviations}

ARIs: Acute Respiratory Infections; BR: Birth Recode; Cl: Confidence Intervals; DHS: Demographic and Health Survey; EA: Enumeration Area; LGAs: Local Government Areas; HR: Hazard Ratio; Local Government Areas; NDHS: Nigeria Demographic and Health Survey; NPC: National Population Commission; NPHC: National Population and Housing Census; RC: Reference category; SDG: Sustainable Development Goal; U5M: Under-five mortality.

\section{Limitations}

This study is not without some limitations. The limitation is using Demographic and Health Survey (DHS) data constrained inference of cause-effect relationship given that the data are cross-sectional. Thus, the explanatory variables are only temporal factors associated with child survival. Because of the selfreported information from women, there is the likelihood of reporting bias about neighbourhood poverty and type of cooking fuel used within the house. Finally, the data used are nearly 2 years old, hence the need for recent qualitative data and new studies to investigate the level of impact neighbourhood poverty and use of solid cooking fuels have on under-five health outcome since 2018. Despite these limitations, the findings of this study are important to formulating current policies and programmes for reducing U5M 
by ending poverty in all its forms, attaining universal access to affordable, reliable, sustainable and clean cooking energy in Nigeria.

\section{Declarations}

\section{Ethics approval and consent to participant}

This study utilized NDHS 2018 birth recode (BR) dataset with all personally identifiable information removed. Hence, confidentiality and anonymity are guaranteed. Therefore, no further ethics approval was required. However, permission to download and use the data was obtained from Measure DHS/ICF International, USA.

\section{Consent for publication}

Not applicable

\section{Availability of data and materials}

The NDHS 2018 birth recode (BR) dataset was used for this study and is freely available from the DHS Program archive at https://www.dhsprogram.com/data/dataset.

\section{Conflicting interests}

Not applicable.

\section{Funding}

Not applicable.

\section{Ethical consideration}

This study utilized secondary datasets with all identifier information removed. Hence, confidentiality and anonymity are guaranteed. The formal approval to download and use the data was obtained from the DHS programme.

\section{Acknowledgements}


The author is grateful to the ICF International for making DHS datasets publicly available that made this study possible.

\section{References}

1. United Nations Inter-agency Group for Child Mortality Estimation. Levels \& Trends in Child Mortality: Report 2018, Estimates developed by the United Nations Inter-agency Group for Child Mortality Estimation, United Nations Children's Fund, New York; 2018 UN IGME. https://data.unicef.org/wpcontent/uploads/2018/10/Child-Mortality-Report-2018.pdf

2. National Population Commission (NPC) \& ICF International. Nigeria Demographic and Health Survey 2018.Abuja, Nigeria, and Rockville, Maryland, USA; 2019 NPC \& ICF International. population.gov.ng

3. United Nations International Children's Emergency Fund. Levels \& Trends in Child Mortality Report 2015: Estimates Developed by the UN Inter-agency Group for Child Mortality Estimation. 2015 Report UNICEF, New York. https://www.childmortality.org

4. Ezeh OK, Agho KE, Dibley MJ, Hall JJ, Page AN. Risk factors for postneonatal, infant, child and under-5 mortality in Nigeria: a pooled cross-sectional analysis. BMJ Open. 2015;5:e006779. doi:10.1136/bmjopen-2014-006779.

5. Akinyemi JO, Bamgboye EA, Ayeni O. Trends in neonatal mortality in Nigeria and effects of biodemographic and maternal characteristics. BMC Pediatr. 2015;15:36.

6. World Health Organisation. Household air pollution and health. 2018 WHO. https://www.who.int/news-room/fact-sheets/detail/household-air-pollution-and-health

7. Nolte CG, Schauer JJ, Cass GR, Simoneit BR. Highly polar organic compounds present in wood smoke and in the ambient atmosphere. Environ Sci Technol. 2001;35(10):1912-9.

8. Ezzati M, Kammen DM. Indoor air pollution from biomass combustion and acute respiratory infections in Kenya: an exposure-response study. Lancet. 2001;358(9282):619-24.

9. Zelikoff JT, Chen LC, Cohen MD, Schlesinger RB. The toxicology of inhaled woodsmoke. J Toxicol Environ Health B Crit Rev. 2002;5(3):269-82.

10. Smith KR, Mehta S, Maeusezahl-Feuz M. Indoor air pollution from household use of solid fuels. In: World Health Organization, editor. Environmental and occupational risk factors. 2005;1435-94.

11. Naeher L, Brauer M, Lipsett M, Zelikoff J, Simpson C, Koenig J, Smith KR. Woodsmoke health effects: a review. Inhal Toxicol. 2007;19(1):67-106.

12. Wargocki P, Wyon DP. Providing better thermal and air quality conditions in school classrooms would be cost-effective. Build Environ. 2013;59:581-9.

13. Thabethe NDL, Engelbrecht JC, Wright CY, Oosthuizen MA. Human health risks posed by exposure to PM10 for four life stages in a low socioeconomic community in South Africa. Pan Afr Med J. 2014;18:206.

14. Rana J, Uddin J, Peltier R, Oulhote Y. Associations between Indoor Air Pollution and Acute Respiratory Infections among Under-Five Children in Afghanistan: Do SES and Sex Matter? J. Environ. Res. 
Public Health. 2019; 16:2910.

15. Adepoju AO, Akanni O, Falusi AO. Determinants of child mortality in rural Nigeria. World Rural Observ. 2012;4(2):38-45.

16. Lampert T, Kuntz B. Effects of poverty for health and health behaviour of children and adolescents: Results from KiGGS Wave 2. Bundesgesundheitsblatt, Gesundheitsforschung, Gesundheitsschutz. 2019; 62(10):1263-1274.

17. Jans J, Johansson P, Nilsson JP. (2018). Economic status, air quality, and child health: Evidence from inversion episodes. J HealthEcon. 2018;61:220-232.

18. Bassani DG, Jha P, Dhingra N, Kumar R. Child mortality from solid-fuel use in India: a nationallyrepresentative case-control study. BMC Public Health. 2010;10:491.

19. Khan MN, Islam MM, Islam MR, Rahman MM. Household air pollution from cooking and risk of adverse health and birth outcomes in Bangladesh: a nationwide population-based study. Environ Health. 2017;16:57.

20. World Health Organization. Children: reducing mortality. 2019 WHO. https://www.who.int/newsroom/fact-sheets/detail/children-reducing mortality\#_ftnref1

21. Ullah MB, Mridha MK, Arnold CD, Matias SL, Khan MSA, Siddiqui Z, Hossain M, et al. Factors associated with diarrhoea and acute respiratory infection in children under two years of age in rural Bangladesh. BMC Pediatr. 2019;19:386.

22. World Health Organisation and United Nations Children's Fund. Progress on drinking water, sanitation and hygiene- update and SDG baselines. Geneva: World Health Organization (WHO) and the United Nations Children's Fund (UNICEF), 2017. Licence: CC BY-NC-SA 3.0 IGO.

23. Noonan CW, Semmens EO, Ware D, Smith P, Boyer BB, Erdei E, Hopkins SE, et al. Woodstove interventions and child respiratory infections in rural communities: Kids Air rationale and methods. Contemp Clin Trials. 2020; 89:105909.

24. Uddin J, Hossain Z, Ullah MO. Child Mortality in a Developing Country: A Statistical Analysis. Appl. Quant. Methods. 2009;4:270-283.

25. Chowdhury MRK, Khan MMH, Rafiqul Islam M, Perera NK, Shumack MK, Kader M. Low maternal education and socio-economic status were associated with household food insecurity in children under five with diarrhoea in Bangladesh. Acta Paediatr, 2016;105(5):555-61.

26. Nasir ZA, Murtaza F, Colbeck I. Role of poverty in fuel choice and exposure to indoor air pollution in Pakistan. J Integr Environ Sci. 2015;12(2):107-17.

27. Salim M, Pintu P, Pradip C.Impact of maternal education on under-five mortality of children in India: Insights from the National Family Health Survey, 2005-2006 and 2015-2016. Death Studies. 2019; doi:1080/07481187.2019.1692970.

28. Imo CK, Isiugo-Abanihe UC, Chikezie DC. Socio-economic determinants of under-five children health outcome among childbearing mothers of Abia State, Nigeria. J. Sociol. Anthropol. 2017;9(2):17-27. 
29. Adesanya OA, Darboe A, Rojas BM, Abiodun DE, Beogo I. Factors contributing to regional inequalities in acute respiratory infections symptoms among under-five children in Nigeria: a decomposition analysis. Int J Equity Health. 2017;16:140.

30. Ettarh RR, Kimani J. Determinants of under-five mortality in rural and urban Kenya. Rural Remote Health 2012;12:1812.

31. Aigbe GO, Zannu AE. Differentials in infant and child mortality rates in Nigeria: Evidence from the six geopolitical zones. J. Human. Soc. Sci. Res. 2012;2(16):207-14.

32. Samuel OW, Oni GA, Samir KC, Wurzer M, Akinyemi Al. Household use of solid fuel for cooking and under-five mortality in Nigeria. Pop. Stud. 2018;32(1): 4034-4042.

33. Adebowale SA, Morakinyo OM, Ana GR. (2017). Housing materials as predictors of under-five mortality in Nigeria: Evidence from 2013 Demographic and Health Survey. BMC Pediatr. 2017;17:30.

34. Alam DS, Chowdhury MAH, Siddiquee AT, Ahmed S, Hossain MD, Pervin S, Streatfield K. et al. Adult cardiopulmonary mortality and indoor air pollution: a 10-year retrospective cohort study in a lowincome rural setting. Glob Heart. 2012;7(3):215-21.

35. Mitter SS, Vedanthan R, Islami F, Pourshams A, Khademi H, Kamangar F, Abnet CC, et al. 2016. Household fuel use and cardiovascular disease mortality: Golestan Cohort Study. Circulation. 2016;133(24):2360-2369.

36. Yu K, Qiu G, Chan KH, Lam KB, Kurmi OP, Bennett DA, et al. Association of solid fuel use with risk of cardiovascular and all-cause mortality in rural China. JAMA. 2018; 319(13):1351-1361.

37. United Nations. World economic situation and prospect. 2020 UN. https://www.un.org/development/desa/dpad/

38. Rustein SO, Kiersten J. The DHS Wealth Index. DHS Comparative Reports No. 6. Calverton, Maryland, USA: ORC Macro, 2004.

39. Vandemoortele J. Absorbing social shocks, protecting children and reducing poverty. The role of basic social services. UNICEF staff working papers. Evaluation, Policy and Planning Series EPP-00001, 2000 UNICEF.

40. Nandy S, Irving M, Gordon D, Subramanian S, Smith GD. Poverty, child undernutrition and morbidity: New evidence from India. Bulletin of the World Health Organization. 2005; 83:210-216.

41. Mesike CG, Mojekwu JN. Environmental determinants of child mortality in Nigeria. Sustain. Dev. 2012; 5:65-75.

42. Pamuk ER, Fuchs R, Lutz W. Comparing relative effects of education and economic resources on infant mortality in developing countries. Popul Dev Rev. 2011; 37(4):637-664.

43. Sallis JF, Owen N, Fisher EB. Ecological models of health behaviour. In K Glanz, BK Rimer, K Viswanath (Eds.), Health behaviour and health education: Theory, research, and practice, 2008. pp. 465-486. San Francisco, CA: Jossey-Bass.

44. Stokols D. Establishing and maintaining healthy environments: Toward a social ecology of health promotion. Am Psychol. 1992; 47(1): 6-22. 
45. McLeroy KR, Bibeau D, Steckler A, Glanz K. An ecological perspective on health promotion programs. Health Q. 1988; 15:351-377.

46. Breslow L. Socio-ecological strategies for promoting healthy lifestyles. Am J HealthPromot. 1996;10(4):253-257.

47. Stokols D. (1996). Translating social ecological theory into guidelines for community health promotion. Am J HealthPromot. 1996;10(4):282-298. 